DOSSIÊ TEMÁTICO: Formação de Professores: Projetos em Disputa

\title{
DIRETRIZES CURRICULARES NACIONAIS PARA A FORMAÇÃO INICIAL DE PROFESSORES: PADRONIZAR PARA CONTROLAR?
}

\author{
NATIONAL CURRICULUM GUIDELINES FOR INITIAL TEACHER TRAINING: \\ STANDARDIZE TO CONTROL?
}

\begin{abstract}
DIRECTRIZES CURRICULARES PARA LA FORMACIÓN INICIAL DE PROFESORES: ?ESTANDARIZAR PARA CONTROLAR?
\end{abstract}

\author{
Margareth Fadanelli Simionato \\ Universidade Federal de Santa Catarina - Brasil \\ Márcia de Souza Hobold \\ Universidade Federal de Santa Catarina - Brasil
}

\begin{abstract}
Resumo: Este artigo visa discutir a padronização da formação inicial dos professores, imposta pelo Parecer CNE/CP n 22/2019 e Resolução CNE/CP n 02/2019, como uma "grade" formativa que retira o sujeito e a subjetividade docente do centro do processo formativo, concentrando atenções na dimensão técnica da formação com competências e habilidades predefinidas e estabelecendo estandartes que poderão ser utilizados numa avaliação docente de larga escala em forma de auditoria. Essa normativa fabrica identidades docentes quando prescreve os modos de ser professor/a e do fazer pedagógico e alinha a formação ao conteúdo da BNCC, dentro do modelo gerencial que subjaz ao pacote reformista em curso. Há reordenamento e profunda mudança nos fundamentos, objetivos, conteúdos e estrutura da formação inicial, fortemente associada à cultura de performatividade, voltada à gestão de resultados em consonância com o projeto do capital. São mudanças que expropriam o professor de seu modo de produção, propondo o controle do trabalho docente que busca submeter os saberes tácitos construídos em situações de trabalho e subsidiam sua prática, sua artesania docente. Esse engessamento traz em seu bojo a intencionalidade de expropriação do saber criativo, constituído pelos conteúdos vinculados ao campo da arte, estética, análise crítica de contexto, fortalecimento dos aspectos éticos, etc., inerentes à formação cultural e ao desenvolvimento humano. Considerando essa intencionalidade formativa, delineia-se uma cultura de heterogestão, constituída pela padronização, controle e avaliação (pautas da Nova Gestão Pública -NGE); campo fértil para a implantação da ideologia baseada no livre mercado competitivo que perpetua e intensifica a exploração do trabalhador.
\end{abstract}

Palavras chave: Artesania docente; Formação cultural; Política de formação de professores.

\begin{abstract}
This article aims to discuss the standardization of initial teacher education, imposed by CNE/CP Opinion 22/2019 and CNE / CP Resolution 02/2019, as a formative "grid" that removes the subject and the subjectivity of teachers from the center of the formative process, focusing on the technical dimension of training with predefined skills and abilities and establishing standards that can be used in a large-scale teacher evaluation in the form of an audit. This norm manufactures teaching
\end{abstract}


identities when it prescribes the ways of being a teacher and pedagogical practice and aligns the formation to the content of the BNCC, within the management model that underlies the ongoing reform package. There is a reorganization and profound change in the fundamentals, objectives, contents, and structure of the initial formation, strongly associated with the culture of performance, focused on the management of results in line with the capital project. These are changes that expropriate the teacher from his mode of production, proposing the control of teaching work that seeks to submit the tacit knowledge built in work situations and subsidize his practice, his teaching craftsmanship. This guide brings with it the intentionality of expropriation of creative knowledge, constituted by contents linked to the field of art, aesthetics, critical context analysis, strengthening of ethical aspects, etc., inherent to cultural formation and human development. Considering this formative intentionality, a culture of heterogeneity is outlined, constituted by standardization, control, and evaluation (guidelines of the New Public Management - NPM); fertile field for the implantation of the ideology based on the free competitive market that perpetuates and intensifies the exploitation of the worker.

Keywords: Cultural training; Teachers training policy; Teaching craftsmanship.

Resumen: Este artículo discuti la estandarización de la formación inicial docente, impuesta por el Parecer CNE / CP 22/2019 y la Resolución CNE / CP 02/2019, como una "grada" formativa que quita el sujeto y la subjetividad de los docentes del proceso formativo, centrándose en la dimensión técnica de la formación con destrezas y habilidades predefinidas y estableciendo estándares que pueden ser utilizados en una evaluación docente a gran escala en forma de auditoría. Las identidades docentes se fabrican cuando prescribe las formas de ser y del hacer pedagógico y alinea la formación con los contenidos dela BNCC, dentro del modelo de gestión que sustenta el paquete de reformas en curso. Hayun cambio profundo en los fundamentos, objetivos, contenidos y estructura de la formación inicial, asociada a la cultura del desempeño, enfocada la gestión de resultados del proyecto de capital. Son cambios que expropian el modo de producción de los docentes controlando su labor que somete el conocimiento tácito construido en situaciones laborales y subsidian su práctica, su artesanía docente. Elcurrículo enyesado expropia el conocimiento creativo, constituido por contenidos vinculados al campo del arte, la estética, el análisis del contexto crítico, el fortalecimiento de aspectos éticos, etc., inherentes a la formación cultural y al desarrollo humano. Con esta intencionalidad formativa, se perfila una cultura de heterogeneidad, constituida por la estandarización, control y la evaluación (a la Nueva Gestión Pública - NGE); campo fértil para la implantación de la ideología basada en el libre mercado competitivo que intensifica la explotación del trabajador.

Palabras clave: Artesanìa docente; Formacióncultural; Politica de formación de professores.

\section{Introdução}

O que vivenciamos hoje no campo da educação tem sido o resultado do atendimento de prioridades econômicas, muitas delas oriundas de determinações externas, a partir de diretrizes orientadoras de organizações internacionais (OI), que influenciam diretamente na formulação das políticas públicas para educação em nosso país. O desmonte da educação brasileira não é um processo, mas sim é um projeto que vem sendo levado a efeito desde o final dos anos de 1980, e nos últimos anos atinge o âmago da escola pública e da formação de seus professores.

Por conta das indicações e orientações contidas em documentos produzidos pelos Organismos Internacionais, o professor assume lugar central para o desenvolvimento dos interesses mercantis (MAUÉS; COSTA, 2020). A recente aprovação das Diretrizes 
Curriculares Nacionais para a Formação Inicial de Professores e a instituição daBase Nacional Comum para a Formação Inicial de Professores da Educação Básica (BNC-Formação) alinhada à $\mathrm{BNCC}$ é resultado da emergência atribuída à definição do papel do professor de acordo com o modelo demandado pelo mercado na sustentação de uma sociedade do conhecimento na lógica do capital. Nessa sociedade, o professor deve formar o cidadão produtivo munido de competências em escala global, as quais proporcionem capacidades de constante adaptação às mudanças no sistema produtivo, visto que, na sociedade capitalista, os valores se constroem em consonância com as demandas do mercado.

A educação de qualidade, meta defendida pelos OI, passa a ter uma relação direta com o crescimento econômico em que a lógica economicista empresarial e a cultura gerencialista (PERONI, 2013) demandam por um professor prático, que trabalhe com métodos ativos, com ensino baseado em evidências, e que seja desintelectualizado, ahistórico e tarefeiro, um "professor gerenciado" (PEREIRA; EVANGELISTA, 2019),

Nesse contexto gerencialista e prescritivo, os proponentes das reformas na formação de professores objetivam direcionar o modo de ser e de fazer docente, redefinindo currículos, estabelecendo competências gerais docentes que se configuram como standarts (SHIROMA, 2018), resgatando a ideia de currículo como uma "grade" que impulsiona uma formação formatada. Ou seja, a natureza não material do trabalho docente é uma característica peculiar, na medida em que não é possível separar o produtor de seu produto. Assim, segundo o modo capitalista, a realização do trabalho passa por "mediações" que convençam o professor, pela força ou pela persuasão, a ser artífice de sua própria exploração (KUENZER, 2011).

Nessa perspectiva, a subjetividade docente é alijada do processo formativo, visto que esse implica fabricação de identidades docentes subsidiadas por uma hegemonia discursiva, performática e substitutiva do enriquecimento cultural do professor. A construção desse perfil encontra suporte no alinhamento prescritivo da formação de professores à BNCC, a partir da definição de competências gerais docentes, competências específicas e habilidades vinculadas às dimensões referidas no documento em análise.

Assim sendo, neste artigo discutem-se normatizações para a formação de professores, propostas no Parecer CNE/CP n 22/2019 e na Resolução CNE/CP n 02/2019, as quais levam a uma padronização da formação inicial em que a subjetividade e o sujeito docente são paulatinamente solapados por um redirecionamento ideológico que abala as questões epistemológicas fundantes da condição do professor como trabalhador em uma sociedade capitalista. 
Nesse sentido, o artigo está estruturado da seguinte forma: i) a presente introdução; ii) a formação de professores e o alinhamento à Nova Gestão Pública; iii) hegemonia discursiva e prescrição das identidades docentes; iii) da criação à padronização: hibridização dos discursos, iv) encarceramento da formação cultural e saber criativo: como fica a artesania docente, e por último, as considerações finais.

\section{A formação de professores e o alinhamento à Nova Gestão Pública}

As políticas que definem o desenho curricular da educação brasileira têm sido delineadas desde o final dos anos de 1980, cumprindo um pacote de reformas na redefinição do papel do Estado, aparelhando-o com conhecimentos e ferramentas da gestão empresarial como alternativa às críticas de ineficiência da Administração Pública, criando, assim, a necessidade de modernizar esse Estado. O enxugamento da máquina pública, o ajuste das economias em crise e a supremacia do mercado, respaldado pelo movimento neoliberal, foram campos férteis para a implantação de mudanças que abarcavam, simultaneamente, a iniciativa privada e as ações governamentais. A proposta de descentralizar ações para reduzir o gasto com as políticas sociais, e ao mesmo tempo centralizar com mecanismos de controle e monitoramento, favoreceram o objetivo da modernização do Estado, implantando um novo modelo de gestão conhecido como Nova Gestão Pública (NGP) (ALVES SARAIVA, 2020; CÓSSIO, 2018). Essa modernização contrapõe-se à Administração Pública e, conforme sinalizam Oliveira, Duarte e Clementino (2017), busca “influenciar novos modos não só de organizar e gerir a coisa pública, mas também novos modos de governo, já que ela interfere nos objetivos da ação pública" (p.711).

A crise do Estado-nação é analisada por Hypólito (2011) a partir do enxugamento da estrutura do estado, ou seja, "com a redução de investimentos sociais, com os processos de privatização e retirada do Estado de setores até então exclusivos que passam a ser gerenciados por setores privados" (p.03).

De acordo com Laval (2004) a ideologia empresarial como balizadora das organizações escolares influencia fortemente os sistemas educativos dos países em desenvolvimento, dentre eles o Brasil, sendo respaldada pelas OI na produção de documentos orientadores voltados para a América Latina e Caribe. Nesse cenário, Peroni (2013, p. 18) analisa o caso brasileiro situando as "características de pouca cultura democrática" como uma das grandes dificuldades em avançar nos projetos sociais para educação. Alia-se a isso a questão das estratégias utilizadas pelo capital na superação de sua crise de ordem mundial, implicam, ainda, reordenações nas políticas de reorganização do Estado e da educação. São políticas implementadas pela NGP que 
dão centralidade aos aspectos econômicos em detrimento de aspectos políticos e sociais, deslocando a discussão sobre a educação para a lógica economicista e apregoando a utilização de modelos gerenciais similares aos de mercado. Desse modo, a hegemonia discursiva do fracasso da qualidade da educação pública vai se construindo em uma descentralização da culpa, responsabilizando a escola e, principalmente, seus professores por tamanho insucesso. São discursos orquestrados por grupos compostos de especialistas que atuam como consultores ou fazem parte das grandes organizações internacionais, que, mesmo heterogêneos em funções e objetivos, têm criado e difundido discursos fortemente alicerçados a argumentos comparados, legitimando-se a partir dos resultados das avaliações de larga escala. Produzem orientações aos países para formularem suas políticas e, no caso da educação, naturalizam a necessidade de reformas, "constituindo-se em parte inevitável da globalização e do mercado internacional e de uma economia cada vez mais baseada no conhecimento e que, portanto, exige mudanças radicais na forma de organizar, conceber e desenvolver a educação" (HYPOLITO, 2010, p.1340).

Nesse contexto, indicadores de desempenho, eficácia e eficiência unificam discursos se inserindo nas normativas para a educação. A ênfase recai na gestão por resultados, meritocracia, dentre outros, e, como consequência, o encarceramento do currículo em "grades", bem como a adoção de práticas pedagógicas homogeneizadas e performáticas propostas na atual BNCC e vinculadas às avaliações em larga escala. Sob essa lógica, pesquisas como as de Lima, Sá e Silva (2017) sinalizam alterações provocadas pela NGP. Os autores destacam alguns elementos que integram essas políticas, tais como

[...] a racionalidade técnico-instrumental típica das políticas gerencialistas, o papel das tecnoestruturas e das assessorias internas e externas, o governo pela mensuração dos resultados, o hibridismo entre o público e privado, as novas formas de contratualização competitiva dos chamados "serviços públicos", entre outros que, genericamente, atribuem supremacia ao universo económico-empresarial. (LIMA; SÁ; SILVA, 2017, p. 255).

No que se refere às políticas de formação de professores no Brasil, observa-se que os elementos destacados por Lima, Sá e Silva (2017) reverberam na centralidade de aspectos econômicos em detrimento dos aspectos políticos e sociais, com uma calculada inserção de novos vocabulários que atravessam discursos, retomando concepções já utilizadas por volta da década de 1970, como uma "didática da catequese", conforme alertam Hobold e Farias (2020) ao analisar o desenvolvimento do campo da didática e suas relações com a formação de professores. 
Há um projeto em curso em uma perspectiva atrelada à reestruturação produtiva e ao movimento do capital, sendo parte de um projeto que não é criado no Brasil, mas sim fora dele e que, segundo Dale (2004), faz parte de uma Agenda Globalmente Estruturada para a Educação, em que eficácia é entendida como medida de qualidade na educação (SARAIVA; SOUZA, 2020). São políticas articuladas entre si, materializadas na Resolução CNE/CP n ${ }^{\circ}$ 2/2019, que institui a Base Nacional Comum da Formação de Professores da Educação Básica (BNC-FP) e revoga a Resolução CNE/CP $\mathrm{n}^{\circ}$ 2/2015, fruto de conquistas e lutas das entidades nacionais representantes de educadores e pesquisadores em educação.

A Resolução CNE/CP n 02/2019 não é uma normativa isolada, mas faz parte de um conjunto de legislações de cunho reformista que invertem a lógica, fabricando determinada identidade docente, definindo como os professores devem agir, quais são os problemas práticos que devem resolver, que metodologia devem utilizar e quais conteúdos devem ser trabalhados com os alunos da educação básica, dentro do modelo gerencial que subjaz ao pacote reformista em curso (HYPÓLITO, 2010). A noção de competência profissional docente de viés neoliberal contida na BNC da Formação Inicial traz dimensões que retomam o tecnicismo, subsumindo conceitos como autonomia e criticidade docente ao longo do texto da normativa. Nesse ínterim, para Farias (2019, p. 163), as competências docentes expressas na BNC-FP são como um pacote “com uma lógica homogeneizante e focada nos resultados, que não deixa margem para pensar a formação para a docência numa perspectiva larga e que considere a complexidade do ensinar, a diversidade dos contextos de trabalho, a pluralidade social dos discentes".

\section{Hegemonia discursiva e prescrição da constituição de identidades docentes}

De acordo com Schiroma (2005), por trás da hegemonia discursiva há uma transformação nos discursos possível de se constatar nos documentos produzidos pelas organizações internacionais desde a década de 1970 aos dias atuais. Assim, um determinado conjunto de palavras é compreendido como elemento chave para a mudança proposta por essas organizações na perspectiva de homogeneização das políticas educativas a nível mundial. A construção desse conjunto de documentos, tanto digitalizados quanto impressos, publicizados pela internet, facilita o acesso a dados, informações e justificativas que fundamentam as formulações de políticas educativas nos diferentes países para "popularizar um conjunto de informações e justificativas que tornem as reformas legítimas e almejadas" (SCHIROMA, 2005, p. 429).

No contexto da reestruturação produtiva, o capital passa a exigir novo perfil do trabalhador por competências, e a educação escolar é colocada em xeque. Isso implica novas 
exigências de formação e mudança no corpo profissional, conforme alertam Hobold e Farias (2020, p. 108) ao colocar que a proposição é de formar um "professor que responda rapidamente as situações demandadas em sala de aula, sem necessariamente realizar uma análise crítica dos fatores intervenientes para determinados acontecimentos do cotidiano escolar”. Novos padrões de organização escolar exigem um novo perfil de trabalhador, modificando subjetividades docentes, demandas que expropriam o professor de seu modo de produção, implicando engessamento do trabalho docente, ignorando que "a dimensão político-social impregna toda a prática pedagógica, que querendo ou não está presente nos processos de escolarização" (HOBOLD; FARIAS 2020, p. 109). Nesse sentido, o controle sobre o trabalho docente busca submeter e categorizar os saberes tácitos do professor que subsidiam sua prática, que constituem sua artesania docente ${ }^{1}$.

A noção de conhecimento, no ideário neoliberal, passa por uma ressignificação que se traduz como informação, que se alinha ao conceito de aprendizagens essenciais propostas na BNCC. Essas aprendizagens estão relacionadas à figura de um novo trabalhador que esteja preparado para a adaptabilidade ao mercado de trabalho com aprendizagens básicas, que tenha acesso a uma informação maior, e não ao conhecimento.

Sendo a BNCC orientadora da formação docente, potencializa-se o caráter prescritivo para essa formação, pois, além de retirar a autonomia do currículo das escolas, o faz também no currículo da formação de professores. Centraliza e categoriza o conhecimento em competências alfanuméricas que têm estreita relação com as avaliações de larga escala, responsabilizando o professor pela condução da aprendizagem do aluno e desconsiderando as desigualdades e a possibilidade (ou não) de acesso aos bens culturais das diferentes classes sociais.

\section{Da criação à padronização (hibridização dos discursos)}

Os documentos que reordenam a formação de professores são prescritivos e orientam para a formação de professores tarefeiros, em detrimento de uma gama de conhecimentos importantes ou, como nos traz Nussbaum (2015, p. 8), “outras competências igualmente decisivas, correm o risco de se perder no alvoroço competitivo; desconsiderando-se que [...] para o bem estar interno de qualquer democracia [...], competências ligadas às humanidades e

\footnotetext{
${ }^{1}$ Compreende-se artesania como derivação do artesão, ao que diz respeito às técnicas artesanais. Inclui-se a palavra "docente" assim, artesania docente significa a mobilização dos saberes tácitos construídos pelo professor no decorrer do seu trabalho colocados em prática no processo de produção do conhecimento com seus alunos. Nasce da reflexão sobre a experiência de uma permanente mobilização dos saberes construídos em sala de aula.
} 
às artes, [...] a capacidade de imaginar, com simpatia, a situação difícil em que o outro se encontra" são fundamentais.

Analisando as recomendações do Banco Mundial e da Unesco para as reformas educativas, Schiroma (2018, p. 97) alerta para a desintelectualização e redução de gastos com os professores, propondo a criação de uma "base global de conhecimentos fortes" afirmando a necessidade de avaliações estandardizadas para construção de parâmetros comparativos. Nesse sentido, a proposição desses Organismos Internacionais para a construção de Bases Nacionais Comuns, tanto de competências mensuráveis para a educação básica quanto na formação de professores, evidencia a orientação de viés pragmático, bem como a formação do professorprático em detrimento de sua intelectualização.

Igualmente, o Parecer CNE/CP nº 22/2019, que discorre sobre as Diretrizes Curriculares Nacionais para formação inicial de professores para a Educação Básica e Base Nacional Comum para a Formação Inicial de Professores da Educação Básica (BNC-Formação) anuncia o ineditismo de um "[...] consenso nacional sobre as aprendizagens essenciais, que são consideradas como direito de todos e, portanto, devem ser, ao longo de todas as modalidades e etapas, asseguradas na Educação Básica” (BRASIL, 2019a, p. 01). Consenso de quem? Por quem? As entidades ${ }^{2}$ representativas dos professores ficaram ao largo das decisões, enquanto as fundações, organizações e setor privado avançaram nas determinações. Pereira e Evangelista (2019, p. 71) analisam a influência e o direcionamento da contribuição midiática via matérias publicadas na revista Nova Escola que "disseminaram a ideia de que 'especialistas e docentes da rede pública fizeram a Base' em que cada contribuição em consulta pública on-line foi considerada como autoria, ignorando as críticas feitas pelas entidades representativas de professores.

Enquanto a Resolução CNE/CP n ${ }^{\circ}$ 02/2015 foi o resultado de muitos fóruns de discussão pelas entidades representativas, apresentando uma base de formação para o professor que articulava a formação inicial e a formação continuada na perspectiva da formação humana, essa nova normativa atende a outros interesses, que não o dos próprios professores. Ou seja, o documento segue anunciando a necessidade de garantir sua efetividade e assevera que, para tanto, “[...] os professores devem desenvolver um conjunto de competências profissionais que os qualifique para colocar em prática as dez competências gerais, bem como as aprendizagens essenciais previstas na BNCC [...] (BRASIL, 2019a, p. 01, grifo nosso). Nesse contexto, o que se segue é a proposição de uma regulação da formação e do exercício profissional docente,

${ }^{2}$ Anfope, Anped, CNTE, Anpae, dentre outras. 
evocando o artigo 13 da LDB $\mathrm{N}^{\circ}$ 9394/96 para deslocar o foco do processo ensinoaprendizagem somente para a aprendizagem dos estudantes, em que "[...] a aprendizagem passa a ser a principal incumbência do professor [...], uma vez que a finalidade primordial das atividades de ensino está nos resultados de aprendizagem (BRASIL, 2019a, p. 05)

Da mesma forma, a formação de professores proposta na BNC-FP (Resolução 02/2019, BRASIL, 2019b) alinha-se ao conceito de competências e habilidades da BNCC, construído na hegemonia discursiva, dentro do projeto de desmonte que vem atravessando as últimas décadas. Isto é, são propostas dez competências gerais docentes, desdobradas em competências específicas e vinculadas a três dimensões fundamentais, a saber: conhecimento profissional, prática profissional e engajamento profissional. Não por acaso, as três dimensões finalizam com o termo profissional, ou seja, de que lugar estamos percebendo a formação que está nessa proposta? Para Pereira e Evangelista (2019, p. 82), o processo de criação e implementação da BNCC, balizadora da formação de professores, "radicalizou o processo de expropriação do conhecimento do professor e investiu no aprofundamento de formas de gerenciamento da formação e do trabalho docente", resultando em um professor gerenciado, alijado de sua representatividade e potência política na contribuição da construção da construção de outras relações sociais. Kuenzer (2011), ao discutir a formação de professores para o ensino médio, já alertava para o fato de que o trabalho docente está inscrito no âmbito do trabalho capitalista e disso decorrem as contradições, na medida em que

[...] as propostas curriculares de formação de professores podem estimular as práticas revolucionárias ou retardá-las, à medida que permitam ou não a compreensão do mundo do trabalho capitalista com todas as suas contradições; que possibilitem o desenvolvimento de práticas conservadoras ou estimulem o desenvolvimento de sujeitos críticos e criativos, comprometidos com a construção de outras relações sociais. (KUENZER, 2011, p. 678).

Se, nas concepções ontológicas e epistemológicas que sustentam a BNC-FP (Resolução 02/2019, BRASIL, 2019b), o professor não é um intelectual produtor de conhecimentos, então passa a ser um instrumento de aplicação de conhecimentos, com o agravante do empobrecimento teórico e uma centralidade em uma concepção de prática pedagógica orientada para resultados, semelhantemente a uma "auditoria" verificadora das competências desenvolvidas pelo professor em sua formação inicial. Uma formação que incute a noção de professor-líder, que organiza e gerencia a sala de aula nesse formato. Sob esse mesmo ponto de vista, Shiroma (2018, p. 94) afirma que "a perspectiva gerencialista visa desenhar um líder que saiba como fazer as coisas mais do que pensar de forma mais ampla nas razões pelas quais aquela requisição está sendo executada”. 
Ademais, há um reordenamento e uma mudança nos fundamentos, objetivos, conteúdo e estrutura da formação inicial dos professores fortemente associada a uma cultura de performatividade, voltada para uma gestão de resultados que fazem parte de um conjunto de normativas articuladas entre si e estruturam a educação em consonância com o projeto do capital. Nesse sentido, o incentivo ao lucro leva muitas vezes líderes ansiosos a entender que a ciência e a tecnologia têm papel central no projeto de desenvolvimento em seus governos, aderindo a uma proposta de educação promovida pelo capital, negligenciando conhecimentos de outras áreas como as humanidades e as artes. Isto é, a formação de professores permaneceu nos limites da lógica da reprodução capitalista em que a formação aligeirada e acrítica, sem a compreensão ideológica necessária, produz "a crença de que com um bom percurso formativo inevitavelmente teremos bons professores" (KUENZER, 2011, p. 676).

\section{Encarceramento da formação cultural e saber criativo: como fica a artesania docente...}

A Resolução CNE/CP n ${ }^{\circ}$ 02/2019 propõe uma formação prática em detrimento do conceito de práxiscomo prática social. Uma compreensão pragmática da formação de professores, a partir de uma visão reducionista em que a prática se reduz ao planejamento, à regência e à avaliação dos alunos. Nesse cenário, Ordine (2016, p. 109) alerta para o fato de que "equiparar o ser humano exclusivamente com sua profissão seria um erro gravíssimo: em todo ser humano há algo de essencial que vai muito mais além de seu próprio "ofício"”. Similarmente para Pereira e Evangelista (2019, p. 78), “o saldo para os professores é seu empobrecimento teórico e a centralidade da prática pedagógica orientada para resultados verificáveis por avaliações de larga escala [...]”.

Contrariamente a essa lógica, a Resolução CNE/CP n 02/2015, em seu capítulo V, art.13 definia a estrutura, a carga horária carga horária total (3200h) e os critérios de organização dos cursos. Além de estabelecer a duração mínima do curso $(8$ semestres ou 4 anos), organizava a distribuição da carga horária para as atividades de estágio (400h) e prática (400h), de atividades formativas (2.200h), compreendendo os núcleos I e II, constante no artigo 12, sem definir limites para cada núcleo, bem como definia atividades teórico-práticas (200h) para aprofundamento específico, as quais articulavam os interesses dos estudantes com a formação. Ou seja, nessa Resolução, não há o engessamento de carga horária para trabalhar os conteúdos gerais ou específicos, ficando a decisão a critério da instituição formadora. Uma proposição de abertura, de consenso diante das especificidades de formação e do aprofundamento teórico necessário para a compreensão da prática e da formação de um professor comprometido com o campo de trabalho que, por meioda formação, compreenda 
"historicamente os processos de formação humana em suas articulações com a vida social e produtiva, as teorias e processos pedagógicos, de modo a ser capaz de produzir conhecimento em educação e intervir de maneira competente nos processos pedagógicos amplos e específicos, institucionais e não institucionais" (KUENZER, 2011, p. 684).

Já na Resolução CNE/CP nº 02/2019 é estabelecida a carga horária total mínima, de 3.200 horas, porém essa não fixa o período mínimo para integralização do curso, distribuindo e delimitando a carga horária a ser cursada para cada grupo proposto na organização curricular. Nesse sentido, são atribuídas apenas 800 horas para trabalhara base comum, em que estão os conhecimentos científicos, educacionais e pedagógicos. Sendo concentrada a maior carga horária $(1.600 \mathrm{~h})$ para a aprendizagem de conteúdos diretamente relacionados com a BNCC e destinadas as horas restantes $(800 \mathrm{~h})$ para a "prática pedagógica", dividindo-a igualmente entre estágios e práticas. Nessa proposição, as 200 horas antes destinadas ao aprofundamento específico de acordo com os interesses do estudante foram retiradas, expropriando a autonomia na formação e a oportunidade de enriquecimento científico e/ou cultural. Nesse âmbito, Ordine (2016, p. 109) alerta que, ao focar exclusivamente na profissionalização, corre-se o risco de perder de vista uma dimensão universal da função formativa da educação: nenhuma profissão poderia ser exercida de modo consciente se as competências técnicas que ela exige não estivessem subordinadas a uma formação cultural mais ampla." Assim, o redirecionamento da formação para o professor prático, ou o "professor gerenciado", conforme Pereira e Evangelista (2019), configura-se, dentre outras questões, como contenção da formação e da organização de uma ampla consciência de classe. Dito de outra forma, a crescente precarização do trabalho docente, assim como a institucionalização progressiva dos serviços educacionais e da plataformização do ensino, dicotomizam a relação entre parte e totalidade, expropriando os professores de seus saberes de sua capacidade de engajamento em causas maiores e nas lutas sociais por uma educação pública, gratuita, laica e de qualidade para todos.

Inquestionavelmente, a padronização da formação de professores encerra em si a contenção e condicionamento a um projeto atrelado ao rendimento escolar, avaliações de larga escala, e sistemas de ranqueamento na concepção de qualidade na lógica empresarial medindo a eficiência e eficácia da educação de acordo com padrões definidos externamente (CÓSSIO, 2018). Assim, quando o Artigo $2^{\circ}$ da Resolução CNE/CP n ${ }^{\circ}$ 02/2019 dispõe que essa formação "pressupõe o desenvolvimento pelo licenciado, das competências gerais previstas na BNCCEducação Básica, bem como as aprendizagens essenciais a serem garantidas aos estudantes”, clarifica o encarceramento dessa formação. A esse emparelhamento de conteúdo, metodologias e avaliações, agrega-se a contenção do saber como fruição, na intensa produção de materiais 
didáticos alinhados aos códigos alfanuméricos (ensino fundamental e médio) ou aos direitos de aprendizagem e campos de experiência da educação infantil ${ }^{3}$ propostos na BNCC. Com isso, acaba cerceando possibilidades para uma formação que promova a articulação da ciência, cultura e trabalho no sentido de produção da própria existência. O gosto pelo conhecimento desinteressado ou o "conhecimento inútil", como nos traz Ordine (2016, p. 130), torna-se algo de menor importância, visto que "dificilmente a paixão pela filosofia ou pela poesia, pela história da arte ou pela música poderá surgir a partir da leitura de materiais didáticos que, de simples meios de apoio, acabam por substituir definitivamente as obras das quais falam. Os textos, em suma, tornam-se puros pré-textos."

Para além de um currículo engessado e formatado em uma grade de competências e habilidades, há uma produção sobre o refinamento na docilização do trabalhador e sua adaptabilidade às variações do mercado de trabalho, com a introdução de competências socioemocionais, ou habilidades não cognitivas, inteligência emocional, soft-skills, nas dez competências gerais da BNCC, em maior ênfase nas competências número $9^{4}$ e $10^{5}$. Assim, na proposição dos Organismos Internacionais, o desenvolvimento dessas competências proporciona o êxito pessoal e profissional no século XXI e, por conta disso, devem ser desenvolvidas na escola.

Publicações como a de Ortiz, Hincapié y Paredes (2020, p. 54), financiadas pelo BID, apontam evidências que ratificam a necessidade de "capacitar a los docentes, y desarrollar orientaciones y estrategias para promover el desarrollo de estas habilidades em lãs escuelas." Nesse caso, as autoras apresentam um diagnóstico realizado nos sistemas educativos de 12 países $^{6}$ da América Latina e Caribe, dentre eles o Brasil, sobre a incorporação das habilidades socioemocionais nos sistemas educativos, o papel dos docentes e a formação que esses recebem para desenvolvê-la com seus alunos. Ainda, na proposta de subsidiar a formulação das políticas de formação de professores, sugerem alguns indicativos.

Para asegurar que las habilidades socioemocionales sean promovidas em el contexto escolar, es fundamental que los docentes reciban formación que les permita desarrollar estas habilidades y contar com

\footnotetext{
${ }^{3}$ Aqui nos referimos ao crescente apostilamento verificado na educação infantil nos últimos anos.

${ }^{4}$ Competências Gerais da BNCC: 9. Exercitar a empatia, o diálogo, a resolução de conflitos e a cooperação, fazendo-se respeitar e promovendo o respeito ao outro e aos direitos humanos, com acolhimento e valorização da diversidade de indivíduos e de grupos sociais, seus saberes, identidades, culturas e potencialidades, sem preconceitos de qualquer natureza.

${ }^{5}$ Competências Gerais da BNCC:10. Agir pessoal e coletivamente com autonomia, responsabilidade, flexibilidade, resiliência e determinação, tomando decisões com base em princípios éticos, democráticos, inclusivos, sustentáveis e solidários.

6 Argentina, Bolivia, Brasil, Chile, Colombia, Costa Rica, Ecuador, Honduras, México, Perú, República Dominicana y Uruguay.
} 
herramientas pedagógicas para desarrollarlar en sus estudiantes. (BID, 2020, p.16).

Da mesma forma, o Parecer CNE/CP $n^{\circ}$ 22/2019, ao tratar das competências socioemocionais, define-as como "as capacidades individuais que se manifestam de modo consistente em padrões de pensamentos, sentimentos e comportamentos" (BRASIL, 2019a, p. 12). Tais competências são compreendidas no referido Parecer como facilitadoras do desenvolvimento de estudantes, no sentido de "[...] compreender e construir relações com os outros e consigo mesmo de modo confiante, criativo, resiliente e empático [...]”. Nessa conjuntura, é esperado que o professor formado a partir dessa nova configuração

[...] esteja preparado para articular estratégias e conhecimentos que permitam também desenvolver essas competências socioemocionais em seus estudantes, considerando as especificidades de cada um e estimulando-os em direção ao máximo desenvolvimento possível. Ao longo da formação no nível superior, os licenciados devem construir, portanto, uma base robusta de conhecimento profissional que lhes permita agir sobre a realidade, apoiar as aprendizagens dos estudantes com os quais estão trabalhando [...] (BRASIL, 2019a, p. 13).

Dito de outro modo, incluir a formação para o desenvolvimento das competências socioemocionais, nessa perspectiva, propõe a formação de um trabalhador adaptável ao contexto polivalente e multifuncional do mercado de trabalho, que transfere e readapta as competências laborais performaticamente adaptado e silenciado em sua consciência e humanidade.

Porém, no contexto dessa formação, os conhecimentos culturais e da formação humana estão subsumidos. Nesse âmbito, Dourado (2007, p. 924) já alertava para a necessidade de se considerar diferentes fatores na atuação docente, dentre eles "[...] o acesso a processos formativos que não descurem de uma base sólida de formação, não se reduzindo à disseminação de metodologias e estratégias de aprendizagem".

Por isso, buscamos "lasgrietas", as fissuras possíveis no atual contexto da formação de professores para que a formação cultural, a formação humana e a possibilidade de criação não se reduzam a conteúdos predeterminados ou ainda, na formatação e desenvolvimento de competências socioemocionais. Sem dúvida, precisamos subverter essa ordem, avançar na proposição de uma formação voltada para a cultura e para o saber criativo em situação de trabalho - a artesania docente. Isto é, o processo de construção de saberes mobilizados na prática, mas à luz de aportes teóricos que fundamentam a teoria que orienta a prática. $\mathrm{O}$ fortalecimento de vínculos entre os saberes tácitos e explícitos e a realidade social mais ampla, 
na qual o professor precisa manter estreitas relações para que o vínculo se mantenha e oriente as reflexões e as práticas.

O processo de criação de saberes - a artesania na docência - requer a possibilidade de articular os saberes e a experiência para se desenvolver em contextos pedagógicos em que a incompletude do conhecimento humano impulsiona a busca constante de atualização. Nesse caso, o conhecimento cultural e educacional mais amplo é imprescindível para a formação de professores. A dimensão cultural precisa ser estudada em profundidade pelos professores em sua formação inicial, pois não há como ampliar o repertório cultural centralizando a formação apenas na prática pedagógica da escola, com foco no desenvolvimento de competências cognitivas e habilidades socioemocionais predeterminadas. Nesse sentido, o contato com as artes, o teatro, o cinema, espetáculos de dança e música, a visitação a museus e espaços de exposição de arte podem transformar-se em conteúdos vivos e próximos dos estudantes (BORGES, 2010).

No contexto da discussão que aqui tecemos, colocamos em suspenso o próprio conceito de formação proposto na BNC - Formação. Como então promover formação humana e cultural do professor em meio ao encarceramento curricular contido nessa proposta?

O que significa exatamente formação? Antes de mais nada, como a própria palavra indica, uma relação com o tempo: é introduzir alguém ao passado de sua cultura (no sentido antropológico do termo, isto é, como ordem simbólica ou de relação com o ausente), é despertar alguém para as questões que esse passado engendra para o presente, e é estimular a passagem do instituído ao instituinte. (CHAUÍ, 2003, p. 12).

Assim sendo, a formação do professor para a construção do saber criativo e de uma formação cultural ampliada implica "formar verdadeiramente professores, de um lado, assegurando que conheçam os clássicos de sua área e os principais problemas nela discutidos ao longo de sua história e, de outro lado, levando em consideração o impacto das mudanças filosóficas, científicas e tecnológicas sobre sua disciplina e sobrea formação de seus docentes" (CHAUÍ, 2003, p. 10).

\section{Considerações finais}

Estabelece-se uma relação muito clara entre as proposições dos organismos internacionais e a Nova Gestão Pública, na racionalização de um mercado de formação docente, com alinhamentos e estandardização passíveis de mensuração e comparações internacionais. Isso forma o banco de dados global que esses organismos vêm elaborando para fundamentar e justificar uma educação/ensino por evidências, bem como sustentar o mercado da formação e a 
indústria da avaliação. As políticas públicas para a educação e as recentes políticas para a formação de professores são um nicho muito promissor para a iniciativa privada, ampliando suas possibilidades de lucros e ganhos políticos, seja no alinhamento da formação à BNCC, seja na plataformização do ensino acelerada no contexto pandêmico da Covid-19.

A precarização e a desintelectualização do professor estão a serviço dessa proposta. Conforme alerta Schiroma (2018, p. 96), “evidencia-se o caráter instrumental da educação proposta pelo capital por meio os organismos multilaterais e a natureza interesseira do 'direito à aprendizagem"”. Ou seja, a BNC - Formação para a formação inicial dos professores da Educação Básica ratifica uma formação dentro de um horizonte de matriz de competências, fazendo a relação com uma lógica de avaliações externas estandardizadas e uma postura epistemológica centrada na prática.

Em suma, embora sejam esses os pressupostos impingidos no Parecer $\mathrm{CNE} / \mathrm{CP} \mathrm{n}^{\circ}$ 22/2019 e na Resolução CNE/CP nº 02/2019, defendemos aqui uma formação que não esteja atrelada aos conceitos que fundamentam uma cultura de performatividade voltada para a gestão de resultados que expropria o modo de produção docente, que engessa o trabalho docente, alijando-o de seu saber criativo e de sua artesania.

\section{REFERÊNCIAS}

ALVES SARAIVA, A. M. As matrizes normativas da Nova Gestão Pública e o enfrentamento das desigualdades educacionais. Revista Educação em Questão, v. 58, $n^{\circ}$ 56, 25 ago. 2020. DOI: https://doi.org/10.21680/1981-1802.2020v58n56ID21116

BANCO INTERAMERICANO DE DESAROLLO- BID. ARIAS Ortiz, Elena. HINCAPIÉ, Diana, PAREDES, Diana. Educar para la vida: El desarrollo de las habilidades socioemocionales y el rol de los docentes. BID, .2020. (NT 1908)

BRASIL. Ministério da Educação. Conselho Nacional de Educação. Resolução CNE/CP n. 02/2015, de $1^{\circ}$ de julho de 2015. Define as Diretrizes Curriculares Nacionais para a formação inicial em nível superior (cursos de licenciatura, cursos de formação pedagógica para graduados e cursos de segunda licenciatura) e para a formação continuada. Diário Oficial da União, Brasília, 2 de julho de 2015 - Seção 1 - p. 8-12. Disponível em: $<$ http://portal.mec.gov.br/docman/agosto-2017-pdf/70431-res-cne-cp-002-03072015pdf/file>. Acesso em: 21 set. 2020.

BRASIL. Ministério da Educação. Conselho Nacional de Educação. Parecer CNE/CP n. 22/2019 de 07 de novembro de 2019a. Diretrizes Curriculares Nacionais para a Formação Inicial de Professores para a Educação Básica e Base Nacional Comum para a Formação Inicial de Professores da Educação Básica (BNC-Formação). Disponível em: http://portal.mec.gov.br/index.php?option=com_docman\&view=download\&alias=133091pcp022-19-3\&category_slug=dezembro-2019-pdf\&Itemid=30192> Acesso em 04 já. 2021. 
BRASIL. Ministério da Educação. Conselho Nacional de Educação. Resolução CNE/CP n. 02/2019, de 20 de dezembro de 2019b. Define as Diretrizes Curriculares Nacionais para a Formação Inicial de Professores para a Educação Básica e institui a Base Nacional Comum para a Formação Inicial de Professores da Educação Básica (BNC-Formação). Diário Oficial da União, Brasília, 23 de dezembro de 2019 - Seção 1, p. 115-119.

BRASIL. Ministério da Educação. Base Nacional Comum Curricular (BNCC). Educação é a base. Brasília. 2018. Disponível

em:568http://basenacionalcomum.mec.gov.br/images/BNCC_publicacao.pdf.Acesso em: 04jan 2021.

BRASIL. Lei 9394 de 20 de dezembro de 1996. Estabelece as diretrizes e bases da educação nacional. Disponível em: http://www.planalto.gov.br/ccivil_03/Leis/L9394.htm Acesso em: $28 \mathrm{dez} 2020$.

BORGES, Lívia F.F. Um currículo para a formação de professores. In: A escola mudou: que mude a formação de professores. VEIGA, Ilma P. A.; SILVA, Edileuza F (orgs.) São Paulo: Papirus, 2010.

CHAUÍ, Marilena. A universidade pública sob nova perspectiva. - Revista Brasileira de Educação, nº 24, 2003

CÓSSIO, Maria de Fátima. A nova gestão pública: alguns impactos nas políticas educacionais e na formação de professores. Educação. v.41, n.1, p.6673, 2018.

DOURADO, Luiz F, Políticas e gestão da educação básica no Brasil: limites e perspectivas. Educação e Sociedade. V. 28, n.100 - Especial - p. 921-946, 2007.

FARIAS, Isabel, M. S. O discurso curricular da proposta para BNC da formação de professores da educação básica. Revista Retratos de Escola, Brasília. V.13, n.25, p.155-168.. 2019.

HOBOLD, Márcia S., FARIAS, Isabel M. S. Didática e formação de professores: contributos para o desenvolvimento profissional docente no contexto das DCNs. Revista Cocar, Edição Especial N.8. (p.102-125), 2020.

HYPOLITO, Alvaro M. Políticas curriculares, Estado e regulação. Educação e Sociedade. Campinas, v.31, n.113, p. 1337-1354, out-dez. 2010.

HYPOLITO, Alvaro M. Reorganização gerencialista da escola e trabalho docente. Educação: teoria e prática. V. 21, n.38 out/Nov. 2011.

KUENZER, Acácia. A formação de professores para o ensino médio: velhos problemas, novos desafios. Educação e Sociedade, v.32, n.116, p.667-688, 2011.

LAVAL, Christian. A escola não é uma empresa: o neo-liberalismo em ataque ao ensino público. Londrina: Ed Planta, 2004.

LIMA, Licínio C.; SÁ, Virgínio. SILVA, Guilherme R. O que é democracia na "gestão democrática das escolas?” In: LIMA, Licínio C., SÁ, Virgínio. (orgs). O governo das escolas: democracia, controlo e performatividade. Portugal: Edições Húmus, 2017. 
MAUÉS, Olgaíses C.; COSTA, Maria da Conceição S. A OCDE e a formação docente: a Talis em questão. Revista Práxis Educacional. V.16, n.41, p. 99-124.

Doi:.https://doi.org/10.22481/praxisedu.v16i41.7255

NUSSBAUM, Martha C. Sem fins lucrativos: porque a democracia precisa das humanidades. São Paulo: Editora WMF Martins Fontes, 2015.

ORDINE, Nuccio. A utilidade do inútil: um manifesto. Rio de Janeiro: Zahar, 2016.

PEREIRA, Jennifer. N., EVANGELISTA, Olinda. (2019). Quando o capital educa o educador: BNCC, Nova Escola e Lemann. Movimento-Revista De Educação , (10), 65-90. https://doi.org/10.22409/mov.v0i10.538

PERONI, Vera M. V. A privatização do público: implicações para a democratização da educação. In: PERONI, Vera M. V. (org.) Redefinições das fronteiras entre o público e o privado: implicações para a democratização da educação. Brasília: Liber Livro, 2013.

SARAIVA, Ana M. A.; SOUZA, Juliana F. A formação docente e as organizações internacionais: uma agenda focada na performatividade dos professores e na eficácia escolar. Currículo sem Fronteiras. V. 20, n1, p.129-147, jan/abr.2020.

SCHIROMA, Eneida Oto. Gerencialismo e formação de professores nas agendas das Organizações Multilaterais. Revista Momento: diálogos em educação. v. 27, n.2, p. 88-106, 2018. https://doi.org/10.14295/momento.v27i2.8093

SCHIROMA, Eneida O.; CAMPOS, Roselane F.; GARCIA, Rosalba M.C. Decifrar textos para compreender a política: subsídios teórico-metodológicos para análise de documentos. Perspectiva, Florianópolis, v. 23, n. 02, p. 427-446, 2005.

\section{SOBRE AS AUTORAS:}

\section{Margareth Fadanelli Simionato}

Pós Doutoranda - Educação. UFSC- Integrante do Grupo de Estudos e Pesquisas: Formação de Professores e Práticas de Ensino - FOPPE e do Grupo de Pesquisa Trabalho, Movimentos Sociais e Educação. E-mail: margarethfadanelli@gmail.com

(iD https://qa.orcid.org/0000-0003-2461-7155

\section{Márcia de Souza Hobold}

Universidade Federal de Santa Catarina - UFSC. Doutora em Educação pela PUC SP. Professora do Programa de Pós-Graduação em Educação - PPGE da Universidade Federal de Santa Catarina (UFSC). Líder do Grupo de Estudos e Pesquisas: Formação de Professores e Práticas de Ensino - FOPPE. Bolsista de Produtividade em Pesquisa do CNPq. E-mail: mhobold@gmail.com

iD https://orcid.org/0000-0002-4179-608X 